\title{
Basal insulin persistence in Brazilian participants with T2DM
}

\author{
(DD) Denise Reis Franco ${ }^{1}$ \\ (iD) Magaly Perez-Nieves ${ }^{2}$ \\ (iD) Jasmina I Ivanova ${ }^{3}$ \\ (iD) Dachuang $\mathrm{Cao}^{2}$ \\ (D) Marcela Saturnino Caselato Vaz
}

1. CPClin - Centro de Pesquisa Clínica, São Paulo, SP, Brasil 2. Eli Lilly and Company, Indianapolis, IN, USA 3. Analysis Group, Inc., New York, NY, USA 4. Eli Lilly Brasil, São Paulo, SP, Brasil

http://dx.doi.org/10.1590/1806-9282.65.10.1254

\begin{abstract}
SUMMARY
OBJECTIVE: Real-world effectiveness of basal insulin therapy is affected by poor treatment persistence, often occurring soon after initiation. This analysis is part of an international cross-sectional study conducted in T2DM patients and is intended to describe the reasons behind non-persistence to insulin therapy in Brasil.

METHODS: Responders to an online survey in seven countries were classified as continuers (no gap of $\geq 7$ days), interrupters (interrupted therapy for $\geq 7$ days within first 6 months, then restarted), and discontinuers (terminated therapy for $\geq 7$ days within first 6 months, and did not start it again before the survey). We present the results from the Brazilian cohort.

RESULTS: Of 942 global respondents, 156 were from Brasil, with a mean age of 34 years and a mean of 5.8 years since T2DM diagnosis. Reasons contributing to insulin continuation $(n=50)$ were improved glycemic control (82\%) and improved physical feeling (50\%). Common reasons for interruption ( $n=51)$ or discontinuation ( $n=55)$ were, respectively, weight gain (47.1\%, 43.6\%), hypoglycemia (45.1\%, $38.2 \%)$, and pain from injections (39.2\%, 49.1\%). However, not all patients who reported weight gain and hypoglycemia as a reason for interruption or discontinuation experienced these: 16/24 (66.7\%) and 22/24 (91.7\%) participants had weight gain, and 13/23 (56.5\%) and 15/21 (71.4\%) had hypoglycemia, respectively. The most important reason for possible re-initiation for interrupters and discontinuers, respectively, was persuasion by the physician/HCP $(80.4 \%, 72.7 \%)$.
\end{abstract}

CONCLUSION: The benefits of basal insulin therapy motivated continuers to persist with the treatment; experienced or anticipated side effects contributed to interruption and discontinuation. Physician and patient training is key in the treatment of diabetes.

KEYWORDS: Diabetes Mellitus, Type 2. Insulin. Medication Adherence.

\section{INTRODUCTION}

An unprecedented increase in the incidence and prevalence of diabetes is seen globally. ${ }^{1}$ The condition has an estimated prevalence of $8.7 \%$, and 12.5 million individuals between 20 and 79 years of age have diabetes in Brasil, which places the country in fourth place worldwide, behind China, India, and the USA. Out of that total, 5.7 million individuals (46\%) have undiagnosed diabetes. ${ }^{2,3}$
Many patients in Brasil do not achieve appropriate glycemic control in real-life settings despite advances in treatment options and increased awareness of the risk of diabetes complications related to higher hemoglobin A1c (HbA1c). ${ }^{3-10}$ In a multicenter study, 73\% patients with type 2 diabetes mellitus (T2DM) in Brasil had HbA1c $\geq 7 \%$; when considering only patients who use insulin, this number increased to

DATE OF SUBMISSION: 07-JUn-2019

DATE OF ACCEPTANCE: 11-Jun-2019

CORRESPONDING AUTHOR: Eli Lilly Brasil

Av Morumbi, 8264 - São Paulo, Brasil - Phone: 11-973935112 - São Paulo - SP - Brasil

E-mail:m.vaz@lilly.com 
90\%. ${ }^{9}$ An online survey found that only $25 \%$ of Brasilian physicians would initiate a combination therapy at the start of the treatment despite acknowledging the scientific evidence behind early introduction of combination therapy. ${ }^{4}$ Although insulin has shown the highest efficacy among all antihyperglycemic medication options for lowering blood glucose (BG) levels, ${ }^{11}$ it still remains a challenge to overcome possible barriers throughout the milestones in insulin treatment: the initiation, persistence, adherence, and intensification. ${ }^{12}$

Major barriers to insulin therapy from a Brazilian physician's/health care professional (HCP)'s perspective reported in the literature are as follows: fear for their patients' safety, including weight gain and hypoglycemia, limited time and financial resources, and lack of proper training to translate this complex disease management to patients and families. ${ }^{3-5,13}$ From a patient's perspective, possible barriers to insulin therapy are fear and risk of potential side effects (hypoglycemia and weight gain), negative perception of treatment and perceived lack of efficacy, negative impact on lifestyle and injection phobia, and worsening of diabetes reflecting in personal failure. ${ }^{4,13,14}$ Physicians and patients are often reluctant to initiate and intensify insulin therapy. This leads to poor adherence and persistence of insulin therapy resulting in poor glycemic control and increased complications of diabetes. ${ }^{4,9,15-17}$

What motivates patients to start and continue on insulin, and what are the reasons behind interrupting and discontinuing insulin therapy? Knowledge of those aspects could help physicians/HCPs take adequate measures at the start of and during insulin therapy to help patients overcome barriers and achieve glycemic control.

We conducted an online survey in patients with T2DM from seven countries to evaluate participants' insulin initiation experience and the reasons behind different persistence patterns (continuers, interrupters, and discontinuers). ${ }^{12,18}$ Since socioeconomic factors, besides others, differ between countries, we report in this manuscript the country-specific results from Brasil.

\section{METHODS}

\section{Participants and Study Design}

A cross-sectional online survey was conducted with 942 respondents from Brasil and six other coun- tries (Germany, France, Japan, Spain, the UK, and the USA) between July and September 2015. Overall, the study design, inclusion criteria, patterns of persistence, and results have been outlined in detail elsewhere. ${ }^{12,18}$ In brief, participants from Brasil were identified from the Branded, Survey Sampling International (SSI) and Toluna market research panels of volunteers who agreed to be contacted about studies. Participants enrolled in the survey were asked to describe if there had been a period of 7 or more days, within the first 6 months of starting on basal insulin, when they did not use it. According to their patterns of treatment persistence, they were classified into three cohorts: Continuers were participants with no interruption of at least 7 days in the basal insulin treatment between treatment initiation and participation in the survey. Interrupters were participants who interrupted basal insulin for at least $\geq 7$ days within the first 6 months after initiation and had restarted by the time of the online survey; and discontinuers were participants who stopped basal insulin use within the first 6 months after treatment initiation and did not restart on any basal insulin before the survey.

\section{Data Collection}

The survey investigated participants' concerns and experiences with insulin initiation and use, and the reasons contributing to their different patterns of persistence. Eligible participants responded on demographic and socioeconomic characteristics, disease and treatment history, basal insulin initiation experience (e.g., concerns before initiating insulin, experience, and challenges while taking basal insulin, impact of insulin on different aspects of disease control and life), resources available during initiation and use such as training, support/assistance, and reasons for different persistence patterns. No information regarding personal identification was collected as part of the study to minimize risks to participants. Exemption from ethical review was granted by the Western Institutional Review Board, Puyallup, WA, USA, due to minimal risk to participants.

\section{Statistical Analysis}

All data evaluated for the Brasil subpopulation were analyzed either collectively or separately for the three cohorts of persistence patterns, ie., continuers, interrupters, and discontinuers. Statistical 
analyses were exploratory only. Pairwise comparisons between persistence groups were made using t-tests for continuous variables and chi-square tests or Fisher's exact tests for categorical variables. Given the moderate sample size and the nature of the exploratory analysis, the p-values generated were only used to assist in the identification of potential differences between cohorts and were not adjusted for multiple comparisons. All data are presented descriptively only. Analyses were performed using SAS v.9.3 (Cary, NC) software.

\section{RESULTS}

\section{Participant Characteristics}

Overall, 156 individuals from Brasil participated in the online survey and were younger, more educated, and in larger number compared to individuals in the global cohort (Supplemental Table 1). The mean duration of T2DM was 5.8 years, and almost half of the participants initiated basal insulin treatment between 7 and 12 months before the survey. Continuers and interrupters were more likely to be male $(p<0.05$ for both).

\section{Insulin Initiation and Use Experience}

Motivators to start basal insulin therapy

Most commonly, Brazilian respondents were motivated to start basal insulin because of encouragement by HCP, concerns about developing diabetes complications, and the expectation for improved glycemic control $(69.2 \%, 46.2 \%$, and $42.9 \%$, respectively). More than half of the participants (55.8\%) noted that their views were very/fully considered when initiating insulin, while $26.3 \%$ of participants felt they were somewhat considered, and $17.9 \%$ felt they were slightly/not at all considered, with no notable differences between groups (Table 1).

\section{Participants' feelings when considering insulin}

Most of the respondents agreed/strongly agreed that insulin would help manage diabetes, shared fear of developing complications from diabetes, and felt that insulin recommendation indicated that their diabetes was worsening $(87.2 \%, 78.8 \%$, and $71.8 \%$, respectively). Although similar proportions among the persistence groups agreed to those feelings, interrupters were more likely to believe that insulin was not necessary compared to continuers (49.0\% vs. $24 \%$; $p<0.05)$. In addition, interrupters and discontinuers were more likely to feel a sense of failure compared with continuers $(39.2 \%, 38.2 \%$, and 20\%; $\mathrm{p}<0.05$ for both; Table 1).

Participants' concerns before and after one week of insulin

The main concerns before starting insulin therapy were related to the proper storage of insulin (73.1\%), potentially frequent hypoglycemia (71.2\%), and becoming insulin-dependent (69.2\%). Continuers were less likely to be concerned about monitoring BG levels compared to discontinuers and about injecting insulin in front of others compared to interrupters (50\% vs. $69.1 \%$ and $74.5 \%$, respectively; $p<0.05$ for both). Continuers had fewer concerns about paying for insulin therapy compared with interrupters (36.0\% vs. $60.8 \%$, $\mathrm{p}<0.05$ ).

After one week of insulin therapy, the number of concerns decreased throughout, and the order of importance of concerns changed. Now, the most common concerns were about weight gain (55.8\%), frequent hypoglycemia (54.5\%), insulin dependence (51.9\%), mistakes in self-injection, injection in front of others, and need to visit physician/nurse more often (all, 47.4\%). Continuers consistently had fewer concerns compared to interrupters and discontinuers, except for body weight $(p<0.05)$. Overall, the mean number of concerns decreased after one week of insulin treatment from 8.8 to 6.4 , among the persistence groups. Before the treatment, interrupters reported more concerns compared to continuers $(p=0.0285)$. After one week of treatment, interrupters and discontinuers reported more concerns compared to continuers $(\mathrm{p}=0.0002$ and $\mathrm{p}<0.0001$; Table 1).

\section{Challenges during the first week of insulin use}

More than a third of the participants perceived injecting insulin, titration, and remembering to inject regularly difficult/very difficult $(38.5 \%, 35.9 \%$, and $32.7 \%$, respectively). Further, the following were considered difficult/very difficult during the first week of insulin use: dealing with emotions about needing insulin (29.5\%), proper storage (28.8\%), feeling confident about treating hypoglycemia (28.2\%), making time to inject and worries about family/friends' reaction (26.3\%, each) and more frequent BG levels monitoring (25.6\%). The mean number of challenges overall and among persistence groups was 2.7 , with no notable differences (Table 1). 
TABLE 1. INSULIN INITIATION AND USE EXPERIENCE.

\begin{tabular}{|c|c|c|c|c|c|c|c|}
\hline & \multicolumn{4}{|c|}{ Brasil cohort } & \multicolumn{3}{|l|}{ P-value } \\
\hline & \multirow{2}{*}{$\begin{array}{l}\begin{array}{l}\text { Over- } \\
\text { alla }\end{array} \\
(n=156)\end{array}$} & \multirow{2}{*}{$\begin{array}{l}\begin{array}{l}\text { Con- } \\
\text { tinuersb }\end{array} \\
(n=50)\end{array}$} & \multirow{2}{*}{\begin{tabular}{|l} 
Inter- \\
ruptersc \\
$(n=51)$
\end{tabular}} & \multirow{2}{*}{$\begin{array}{l}\text { Discon- } \\
\text { tinuersd }\end{array}$} & \multirow{2}{*}{$\begin{array}{l}\text { Con- } \\
\text { tinuers } \\
\text { vs Inter- } \\
\text { rupters }\end{array}$} & \multirow{2}{*}{$\begin{array}{l}\text { Continu- } \\
\text { ers vs } \\
\text { Discon- } \\
\text { tinuers }\end{array}$} & \multirow{2}{*}{$\begin{array}{l}\text { Inter- } \\
\text { rupters vs } \\
\text { Discon- } \\
\text { tinuers }\end{array}$} \\
\hline & & & & & & & \\
\hline \multicolumn{8}{|l|}{ Respondents motivations for starting insulin, $\%$} \\
\hline Encouragement from a physician/healthcare provider & 69.2 & 58.0 & 78.4 & 70.9 & * & & \\
\hline Improved glycemic control & 42.9 & 48.0 & 49.0 & 32.7 & & & \\
\hline Concern about developing complications of diabetes & 46.2 & 48.0 & 41.2 & 49.1 & & & \\
\hline Preference for injections over pills & 17.9 & 6.0 & 23.5 & 23.6 & * & * & \\
\hline Inability to tolerate other antihyperglycemic medications & 4.5 & 4.0 & 3.9 & 5.5 & & & \\
\hline \multicolumn{8}{|l|}{ Sources of recommendations to start insulin, \% } \\
\hline Primary care physician & 57.1 & 54.0 & 52.9 & 63.6 & & & \\
\hline Another individual in physician's office & 1.9 & 0.0 & 3.9 & 1.8 & & & \\
\hline Endocrinologist & 31.4 & 38.0 & 35.3 & 21.8 & & & \\
\hline Diabetes educator & 9.0 & 8.0 & 5.9 & 12.7 & & & \\
\hline Respondent & 0.6 & 0.0 & 2.0 & 0.0 & & & \\
\hline \multicolumn{8}{|l|}{ Provider's reasons for recommendation to start insulin, \% } \\
\hline Improved glycemic control & 74.4 & 72.0 & 78.4 & 72.7 & & & \\
\hline Prevention of complications of diabetes & 61.5 & 64.0 & 52.9 & 67.3 & & & \\
\hline Inability to tolerate other antihyperglycemic medications & 9.6 & 8.0 & 5.9 & 14.5 & & & \\
\hline \multicolumn{8}{|l|}{ Degree to which the respondent felt views were considered, \% } \\
\hline Not at all/slightly & 17.9 & 20.0 & 21.6 & 12.7 & & & \\
\hline Somewhat & 26.3 & 30.0 & 15.7 & 32.7 & & & \\
\hline Very/fully & 55.8 & 50.0 & 62.7 & 54.5 & & & \\
\hline \multicolumn{8}{|l|}{ Feelings when considering insulin, $\%$ agree/strongly agree } \\
\hline Sense of failure & 32.7 & 20.0 & 39.2 & 38.2 & * & * & \\
\hline Reassurance that insulin would help manage diabetes & 87.2 & 86.0 & 92.2 & 83.6 & & & \\
\hline Belief that insulin was not necessary & 34.6 & 24.0 & 49.0 & 30.9 & * & & \\
\hline Feeling that insulin indicated that diabetes was worsening & 71.8 & 74.0 & 72.5 & 69.1 & & & \\
\hline Fear of developing complications of diabetes & 78.8 & 80.0 & 80.4 & 76.4 & & & \\
\hline \multicolumn{8}{|l|}{ Concerns before starting insulin, \% agree/strongly agree } \\
\hline Worry that insulin would not provide glycemic control & 50.0 & 38.0 & 56.9 & 54.5 & & & \\
\hline Fear of self-injection & 59.6 & 52.0 & 64.7 & 61.8 & & & \\
\hline Fear of making mistakes during self-injection & 68.6 & 64.0 & 72.5 & 69.1 & & & \\
\hline Worry that scarring or bruising would result from injections & 59.6 & 50.0 & 68.6 & 60.0 & & & \\
\hline Worry about proper insulin storage & 73.1 & 66.0 & 82.4 & 70.9 & & & \\
\hline Concern about carrying insulin around & 67.3 & 66.0 & 74.5 & 61.8 & & & \\
\hline Worry that regular insulin use would interfere with daily activities & 63.5 & 56.0 & 72.5 & 61.8 & & & \\
\hline Concern that he/she would need to visit physician/nurse more often & 60.3 & 50.0 & 64.7 & 65.5 & & & \\
\hline Concern that he/she would need to monitor blood glucose more often & 62.2 & 50.0 & 66.7 & 69.1 & & * & \\
\hline Concern about potentially frequent hypoglycemia & 71.2 & 68.0 & 72.5 & 72.7 & & & \\
\hline Concern about becoming insulin dependent & 69.2 & 72.0 & 64.7 & 70.9 & & & \\
\hline Concern about the ability to pay for insulin therapy & 48.7 & 36.0 & 60.8 & 49.1 & * & & \\
\hline Worry about potential weight gain & 61.5 & 58.0 & 62.7 & 63.6 & & & \\
\hline Worry about injecting insulin in front of other people & 62.2 & 50.0 & 74.5 & 61.8 & * & & \\
\hline Number of concerns before starting insulin, mean (SD) & $8.8(4.3)$ & $7.8(4.0)$ & $9.6(4.3)$ & $8.9(4.4)$ & * & & \\
\hline \multicolumn{8}{|l|}{ Concerns after one week of using insulin, $\%$ agree/strongly agree } \\
\hline Worry that insulin will not provide glycemic control & 42.3 & 18.0 & 54.9 & 52.7 & * & * & \\
\hline Discomfort regarding self-injection & 46.8 & 24.0 & 51.0 & 63.6 & * & * & \\
\hline Fear of making mistakes during self-injection & 47.4 & 28.0 & 47.1 & 65.5 & * & * & \\
\hline Bothered by scarring or bruising resulting from injections & 46.2 & 28.0 & 51.0 & 58.2 & * & * & \\
\hline Burdened by proper insulin storage & 42.3 & 24.0 & 52.9 & 49.1 & * & * & \\
\hline Burdened by carrying insulin around & 39.7 & 26.0 & 49.0 & 43.6 & * & & \\
\hline
\end{tabular}




\begin{tabular}{|c|c|c|c|c|c|c|c|}
\hline & \multicolumn{4}{|c|}{ Brasil cohort } & \multicolumn{3}{|l|}{ P-value } \\
\hline & \multirow{2}{*}{$\begin{array}{l}\begin{array}{l}\text { Over- } \\
\text { alla }\end{array} \\
(n=156)\end{array}$} & \multirow{2}{*}{$\begin{array}{l}\begin{array}{l}\text { Con- } \\
\text { tinuersb }\end{array} \\
(n=50)\end{array}$} & \multirow{2}{*}{$\begin{array}{l}\text { Inter- } \\
\text { ruptersc } \\
(n=51)\end{array}$} & \multirow{2}{*}{$\begin{array}{l}\text { Discon- } \\
\text { tinuersd } \\
(n=55)\end{array}$} & \multirow{2}{*}{$\begin{array}{l}\text { Con- } \\
\text { tinuers } \\
\text { vs Inter- } \\
\text { rupters }\end{array}$} & \multirow{2}{*}{$\begin{array}{l}\text { Continu- } \\
\text { ers vs } \\
\text { Discon- } \\
\text { tinuers }\end{array}$} & \multirow{2}{*}{$\begin{array}{l}\text { Inter- } \\
\text { rupters vs } \\
\text { Discon- } \\
\text { tinuers }\end{array}$} \\
\hline & & & & & & & \\
\hline Feeling that regular insulin use interferes with daily activities & 35.9 & 22.0 & 41.2 & 43.6 & * & * & \\
\hline Burdened by the need to visit physician/nurse more often & 47.4 & 30.0 & 56.9 & 54.5 & * & * & \\
\hline Burdened by the need to monitor blood glucose more often & 38.5 & 26.0 & 47.1 & 41.8 & * & & \\
\hline Bothered by frequent hypoglycemia & 54.5 & 40.0 & 60.8 & 61.8 & * & * & \\
\hline Concern about becoming insulin dependent & 51.9 & 36.0 & 58.8 & 60.0 & * & * & \\
\hline Burdened by paying for insulin therapy & 44.9 & 30.0 & 54.9 & 49.1 & * & * & \\
\hline Bothered by weight gain & 55.8 & 48.0 & 62.7 & 56.4 & & & \\
\hline Discomfort injecting insulin in front of other people & 47.4 & 32.0 & 58.8 & 50.9 & * & * & \\
\hline Number of concerns after one week of using insulin, mean (SD) & $6.4(4.8)$ & $4.1(3.2)$ & $7.5(5.3)$ & $7.5(4.8)$ & * & * & \\
\hline \multicolumn{8}{|l|}{ Challenges during the first week of insulin use, \% difficult/very difficult } \\
\hline Injecting insulin & 38.5 & 40.0 & 37.3 & 38.2 & & & \\
\hline More frequent blood glucose monitoring & 25.6 & 28.0 & 25.5 & 23.6 & & & \\
\hline Titration & 35.9 & 44.0 & 33.3 & 30.9 & & & \\
\hline Proper insulin storage & 28.8 & 26.0 & 31.4 & 29.1 & & & \\
\hline Remembering to inject insulin regularly & 32.7 & 32.0 & 35.3 & 30.9 & & & \\
\hline Making time during the day to inject insulin & 26.3 & 26.0 & 25.5 & 27.3 & & & \\
\hline Feeling confident about treating hypoglycemia & 28.2 & 26.0 & 29.4 & 29.1 & & & \\
\hline Dealing with emotions about needing insulin & 29.5 & 28.0 & 27.5 & 32.7 & & & \\
\hline Worry about the reaction to insulin use from friends/family & 26.3 & 20.0 & 25.5 & 32.7 & & & \\
\hline Number of challenges during the first week of insulin use, mean (SD) & $2.7(2.8)$ & $2.7(2.7)$ & $2.7(3.0)$ & $2.7(2.8)$ & & & \\
\hline \multicolumn{8}{|l|}{ Adverse events experienced while taking insulin, \% } \\
\hline Uncontrolled high blood glucose & 23.1 & 14.0 & 39.2 & 16.4 & * & & * \\
\hline Symptoms of hypoglycemia & 43.6 & 42.0 & 43.1 & 45.5 & & & \\
\hline Weight gain & 45.5 & 36.0 & 49.0 & 50.9 & & & \\
\hline Injection site reaction & 33.3 & 32.0 & 31.4 & 36.4 & & & \\
\hline
\end{tabular}

a Within-country results were not weighted $\mathbf{b}$ Continuers had no gaps of $\geq 7$ days in basal insulin treatment. $\mathbf{c}$ Interrupters interrupted basal insulin for $\geq 7$ days within the first 6 months after initiation and since restarted basal insulin. $\mathbf{d}$ Discontinuers stopped using basal insulin for $\geq 7$ days within the first 6 months after initiation and had not restarted basal insulin by the time of the survey $\mathbf{e} p$-values were calculated using t-tests for continuous variables and chi-square tests for categorical variables without adjustment for multiple comparisons. $\mathrm{P}<0.05$ was considered statistically significant and marked with an asterisk $\left(^{*}\right)$.

\section{Impact of insulin use at specific aspects of life}

Overall, most participants stated that insulin use had a somewhat or a very positive impact on physical well-being (77.6\%), daily activities (73.1\%), glycemic control (72.4\%), and having to stay physically active (72.4\%; Figure 1). The impact of insulin was similar across the persistence groups except for three aspects: continuers were more likely to report that (a) insulin had a positive impact on their physical well-being than discontinuers (82.0\% vs. $69.1 \%)$ (b) it had a neutral impact on budget than interrupters (38.0\% vs. $11.8 \%)$, and (c) their perception of themselves as a healthy person ( $36.0 \%$ vs $9.8 \%$; $p<0.05$ ).

\section{Available resources on training and support}

Most respondents, up to $98 \%$, received training on insulin therapy, diabetes in general, self-injection, titration, and diet/exercise before initiating and also while being on insulin therapy. The availability, use, and helpfulness of the training were found to be similar across persistence groups. Training before insulin use was provided mainly by physicians $(78.2 \%)$ followed by nurse/physician's assistants (44.9\%), diabetes educators (28.8\%), and pharmacists (26.9\%). The vast majority of participants preferred in-person training $(71.8 \%)$ to other formats, that is, videos (58.3\%), websites (54.5\%), and written material (42.9\%). Almost all participants (97.4\%) perceived the support of medical personnel as helpful. Other training channels, such as telephone hotline and smartphone applications, were less preferred.

On the degree of self-confidence before first insulin self-injection, overall, $53.2 \%$ of participants rated themselves as being confident or very confident, $32.7 \%$ as somewhat confident, and $14.1 \%$ as not at all confident. Moreover, most participants felt confident 
or very confident about self-injection before the first use, regardless of the persistence group.

\section{Persistence Patterns: Continuers, Interrupt- ers, and Discontinuers}

The most common self-reported reasons for continuing basal insulin therapy were improved glycemic control, physical feeling, the belief that insulin is best for reducing the risk of complications, and improved emotional well-being (Figure 2a). Most participants (74\%) stated more than one reason for continuing.

The most common reasons contributing to interruption were weight gain and hypoglycemia, followed by pain from injections (Figure 2b). However, not all participants who reported weight gain or hypoglycemia experienced these. Among interrupters who reported weight gain as a reason to interrupt, $16(66.7 \%)$ out of 24 actually experienced weight gain. Similarly, for hypoglycemia, among interrupters who reported hypoglycemia as a reason to interrupt, 13 (56.5\%) out of 23 actually experienced hypoglycemia. Although side effects such as weight gain and hypoglycemia were most often noted as reasons for interruption or discontinuation, those rates were not different between continuers, interrupters, and discontinuers (weight gain: $36.0 \%, 49.0 \%$, and $50.9 \%$, respectively; symptoms of hypoglycemia: $42.0 \%$, $43.1 \%$, and $45.5 \%$, respectively). Most participants
(76.5\%) chose more than one reason for interruption, and $72.5 \%$ had more than one interruption; $58.8 \%$ interrupted insulin therapy for a week, and $41.2 \%$ participants had an interruption longer than one week. During the interruption of basal insulin, 49.0\% of participants reported higher BG levels than before, despite changes in lifestyle such as exercise (74.5\%) and diet (68.6\%) and use of oral antidiabetics (51.0\%) and noninsulin injectables (29.4\%).

The most common reasons contributing to discontinuation of basal insulin therapy were pain from injections, weight gain, and hypoglycemia followed by the cost of insulin therapy and inconvenience of using insulin (Figure 2c). Similar to what was found among patients who had interrupted insulin, not all participants who reported weight gain or hypoglycemia as a reason to discontinue insulin therapy experienced these. Among discontinuers who reported weight gain as a reason to discontinue, 22 (91.7\%) out of 24 actually experienced weight gain. Similarly, for hypoglycemia, among discontinuers who reported it, $15(71.4 \%)$ out of 21 actually experienced hypoglycemia. For $72.7 \%$ of participants, multiple reasons led to discontinuation. After discontinuation of basal insulin, 25.5\% of participants reported higher BG levels than before discontinuing it despite changes in lifestyle (diet $78.2 \%$, exercise $70.9 \%$ ) and use of oral antihyperglycemic medications (38.2\%) and other noninsulin injectables (21.8\%).

FIGURE 1. IMPACT OF BASAL INSULIN USE ON SPECIFIC ASPECTS OF PARTICIPANTS' LIVES.

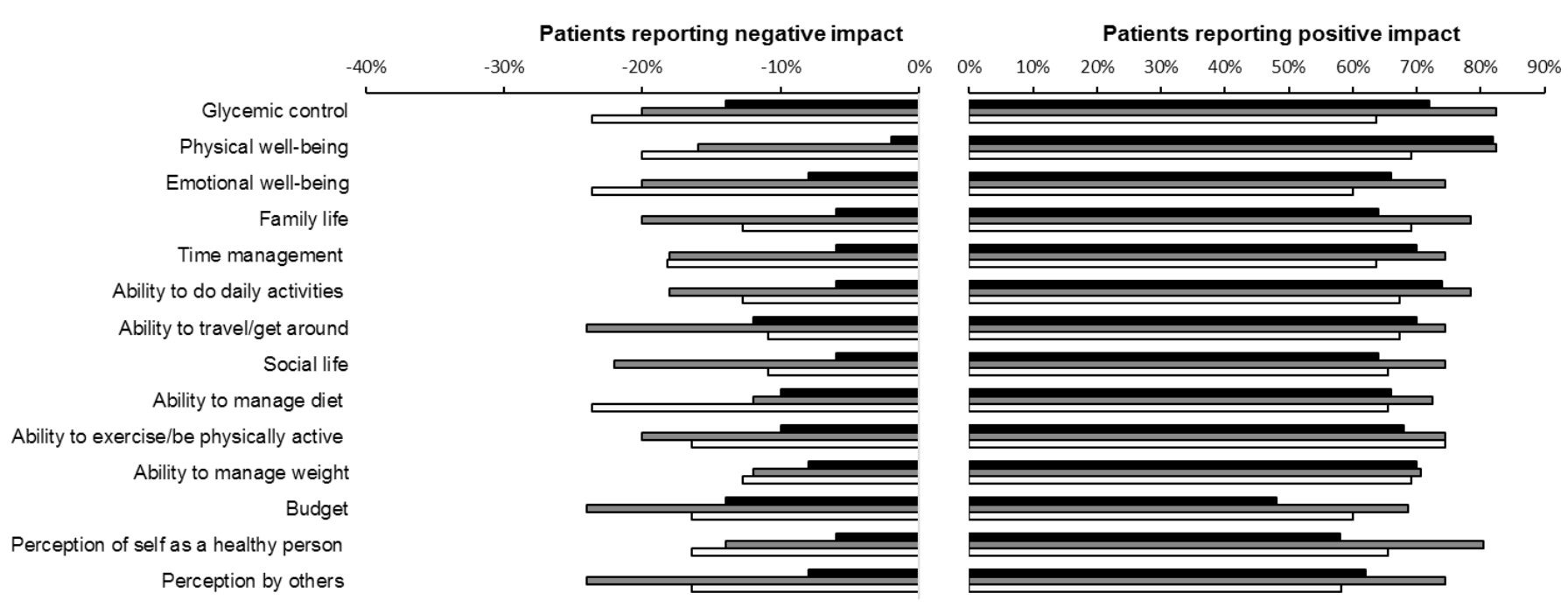

Based on the question: "How has using basal insulin positively or negatively affected the following? For each statement, please choose one of the options." Possible answers: "Very negatively," "somewhat negatively" "neutral/no effect" "somewhat positively," "very positively". Data shown are the percentages of participants rating the effects as "very" or "sonegatively, " somewhat negatively," "neutral/no effect," somewhat positively, "very positively". Data shown are the percentages of participants rating
mewhat" negative for negative impact and "very" or "somewhat" positive for positive impact. Abbreviations: $n$, number of participants per cohort. 
FIGURE 2. A) MOTIVATION TO CONTINUE (N=50), B) FACTORS CONTRIBUTING TO INTERRUPTION $(\mathrm{N}=51)$, AND C) FACTORS CONTRIBUTING TO DISCONTINUATION (N=55) OF BASAL INSULIN.

a) Motivators to continue basal insulin $(n=50)$

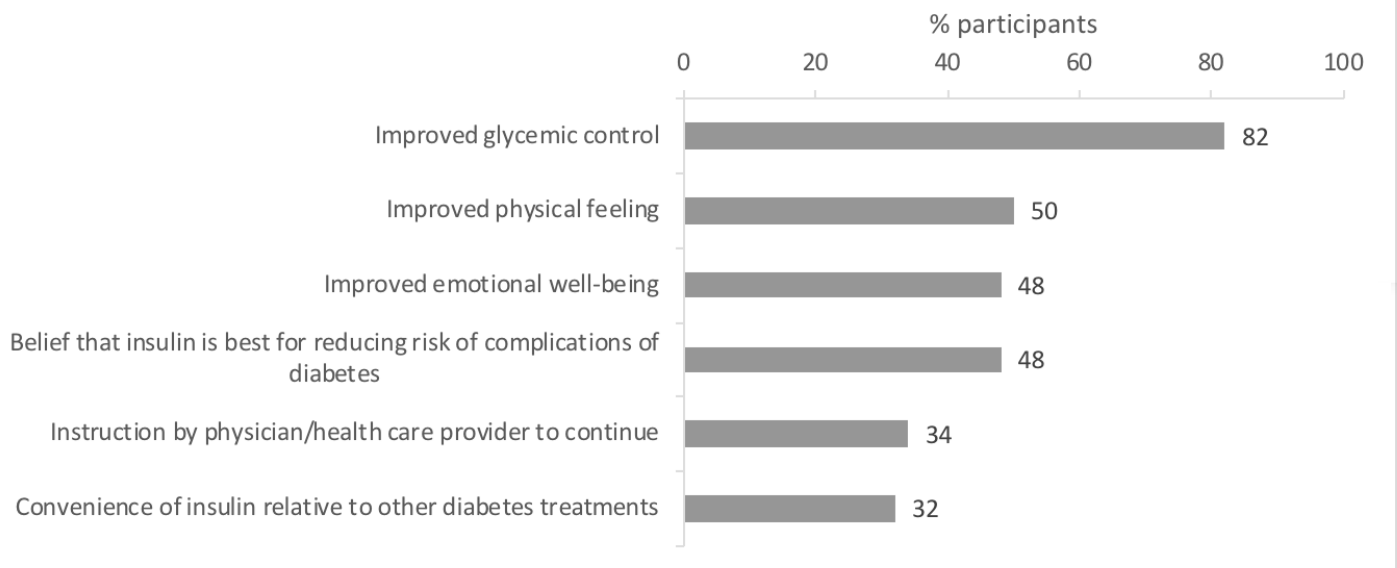

b) Factors* contributing to the interruption of basal insulin $(n=51)$

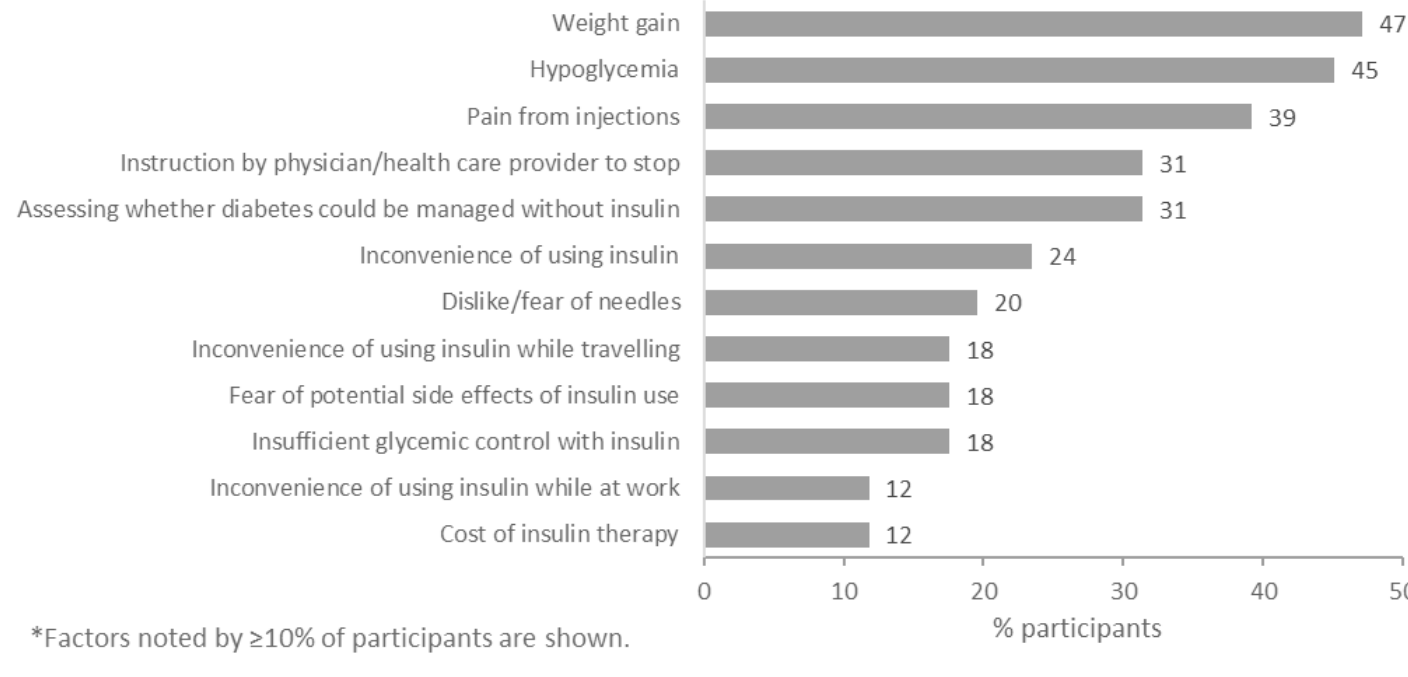

c) Factors ${ }^{*}$ contributing to the discontinuation of basal insulin $(n=55)$

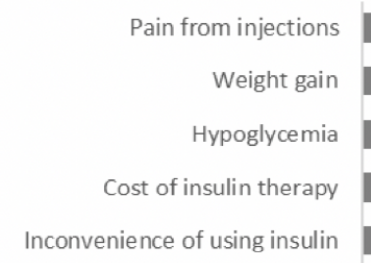

Sense that diabetes could be managed without insulin

Preference of oral antihyperglycemic medications

Instruction by physician/health care provider to stop

Fear of potential side effects of insulin use

Inconvenience of using insulin at home

Inconvenience of using insulin while traveling

Inconvenience of using insulin at work

Dislike/fear of needles
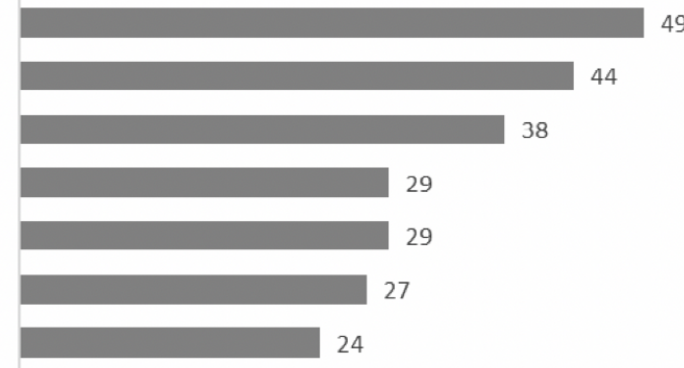

18
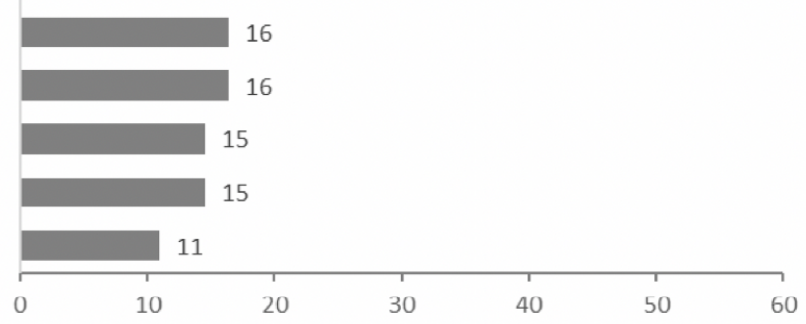

${ }^{*}$ Factors noted by $\geq 10 \%$ of participants are shown.

$\%$ participants 
Reasons and potential reasons for restarting basal insulin among interrupters and discontinuers

The most common reasons contributing to restarting basal insulin therapy among interrupters were persuasion by physician/HCP (80.4\%), persuasion by friends/family (47.1\%), insufficient glycemic control without insulin (37.3\%), and resolution of the issues that led to interruption (13.7\%). Nearly half of early interrupters (45.1\%) chose more than one reason for restarting insulin. Similarly, the most common reasons for potentially restarting basal insulin among discontinuers were persuasion by physician/HCP (72.7\%), insufficient glycemic control without insulin (61.8\%), and persuasion by friends/family (43.6\%). Overall, $56.4 \%$ of discontinuers chose more than one reason for potentially restarting basal insulin.

\section{Adverse Events}

Weight gain (45.5\%) and hypoglycemia (43.6\%) were reported most frequently followed by injection-site reactions (33.3\%) and uncontrolled high blood glucose (23.1\%). Continuers and discontinuers were less likely to report uncontrolled high blood glucose than interrupters $(\mathrm{p}<0.05)$.

\section{DISCUSSION}

This online survey enrolled 156 participants with T2DM, from Brasil, starting on basal insulin therapy, and intended to provide insights into patient-reported factors on insulin initiation and use. Overall, the literature suggests poor glycemic control among patients with T2DM in Brasil, majorly due to delay in initiating insulin therapy and poor adherence to the treatment., 3,9,19 Carefully understanding the factors that contribute to inadequate glycemic control may help change this scenario.

One of the most relevant findings was the importance of the patient-physician/HCP relationship documented in several parts of the study. Support from medical personnel and in-person training were considered very helpful by most participants and were the preferred format of training before and during insulin treatment. Most participants reported that their physicians encouraged and motivated them to initiate insulin treatment. Further, instruction by a HCP was often a reason for continuing (34.0\%), interrupting (31.4\%) and resuming $(80.4 \%)$, discontinuing (18.2\%), and potentially resuming(72.7\%) insulin therapy. From other studies, it is known that physician recommendations are critical factors in patient decisions ${ }^{\mathbf{1 4 , 2 0}}$ and likely to be underestimated. Some reported reasons might have been physician-driven without mentioning the physician in particular ${ }^{12}$ (e.g., interruption to assess whether diabetes could be managed without insulin [31.4\%], insufficient glycemic control with insulin [17.6\%]). Mendes et al. ${ }^{9}$ found that health care delivered by a multi-professional team was associated with improved glycemic control compared to a primary care physician. Furthermore, a recent pilot study of a Community Health-Agent-led self-management training program using motivational interviewing-based approaches in a primary care setting in Brasil demonstrated overall improvements in patients' self-management of diabetes and in the quality of received diabetes care and clinical risk factors. ${ }^{21}$ Diabetes self-management education programs are essential strategies to improve health behaviors. ${ }^{9}$ Usually, a primary care physician undertakes the initial evaluation of a patient with diabetes. ${ }^{3}$ This was also observed in the current study, with more than $50 \%$ of primary care physicians recommending to start basal insulin therapy. In contrast, a recent online survey in Brasil by Vencio et al. ${ }^{4}$ noted that fewer patients were initially seen by a primary care physician (34\%) and more patients recall initial diabetes counseling by a specialist (53\%).

In our study, up to $98 \%$ of participants from Brasil reported to have had training possibilities, mainly provided by physicians, and in-person training was preferred over other channels. More than half of the participants felt their views were considered when starting treatment, allowing the positive experience of shared decision making on later treatment persistence with insulin therapy. The shift from advice-giving to encouraging patients to define their own goals ${ }^{21}$ may translate into better adherence and persistence to insulin therapy. In another study, 50\% of Brazilian patients believed not having had time to explain their fears and concerns. ${ }^{4}$ Furthermore, to improve patient engagement, physicians should focus on the quality of life-based discussions on complications rather than mortality-based discussions. ${ }^{4}$

Across all three persistence patterns (continuers, interrupters, and discontinuers), the vast majority of participants agreed that insulin would help manage diabetes, and, interestingly, more individuals in the interrupters cohort agreed on that. However, overall, 
continuers had fewer concerns regarding the treatment before and after one week of insulin therapy compared to interrupters and discontinuers. Before treatment, patients throughout the persistence groups reported more concerns than one week after treatment initiation. These highlight insufficient education, confidence, and autonomy at the time of insulin prescription. Further, before treatment, more interrupters compared to continuers had more concerns, which may be due to stressful initial situation influencing treatment persistence. Nevertheless, participants, irrespective of their persistence group, experienced the same mean number of challenges (2.7) and the same typical challenges such as injection, titration, and management of hypoglycemia during the first week of treatment. Interestingly, continuers seemed to be convinced by improvements due to insulin treatment (e.g., improved glycemic control, improved well-being physically and emotionally, among others) and was the main motivation to remain on insulin therapy. Instructions and motivation by HCP were less likely a reason for continuing in this group. It could be speculated that this discrepancy between continuers and interrupters/discontinuers could also be due to a more positive attitude/mindset towards treatment through better training and information on diabetes management.

Before and after one week of treatment, the fear of making mistakes during self-injection, among common concerns, was in fourth place. It is likely that training, information, and experienced self-injection over time were not paired with gained confidence in self-injection.

Actual experienced or anticipated side effects such as weight gain and hypoglycemia were often noted as factors for interruption or discontinuation. However, a substantial proportion of patients who cited fear of weight gain or hypoglycemia as reasons to interrupt or discontinue insulin did not actually experience these events. This discrepancy indicates that whether weight gain or hypoglycemia were experienced or only anticipated, its fear seems to be the same. ${ }^{22}$ The proportion of patients that experienced weight gain and hypoglycemia did not differ among continuers, interrupters, and discontinuers. Patient attitudes contributing to resistance to insulin treatment have been identified in several studies; including the belief that taking insulin leads to poor outcomes, such as hypoglycemia, weight gain, and other complications. ${ }^{14}$ Better education and training by HCPs may help patients be prepared with realistic expectations and enable them to treat side effects accordingly and continue the treatment. However, a recent online survey in Brasil demonstrated a high level of disconnect between what physicians thought they had discussed and what patients were able to recall, suggesting an urgent need to identify the deficits in education. ${ }^{4}$ Educational measures should also target the "trainer," such as training physicians and HCPs on insulin benefits and administration, promoting events on the topic, and improving HCPs' awareness about the importance of having good communication with their patients. ${ }^{5,13}$ For physicians/HCPs and patients alike, education and training on T2DM disease management should be the cornerstone in insulin therapy to address the individual needs - challenges, concerns, and feelings. ${ }^{13}$

\section{Limitations}

Several limitations apply to this online survey in Brasil. The persistence category was reported by participants. The participants were evaluated only for 3 to 6 months; thus, there is the possibility of misclassification; for example, continuers may stop later, or discontinuers may restart. In addition, clinical information about the diagnosis or severity of the illness was not captured; therefore, the relationship between clinical measures and basal insulin persistence remains unknown. The sample was not representative of the general diabetes population in Brasil. In particular, younger participants were overrepresented in the survey (mean age 34.2 years), ${ }^{4,6,10}$ higher education and employment status, as were patients for whom the basal insulin was their first antihyperglycemic treatment (39.1\%). Prior to the survey, pre-treatment with other non-insulin injectables was more common in the interrupter and discontinuer cohorts; this is in contrast to findings in the literature which reported a higher likelihood of persistence with prior use. ${ }^{15,17,18}$ Results might have been affected by selection bias, recall bias, and social desirability bias, as with all data based on surveys. Concomitant oral treatment or comorbidities as additional factors affecting treatment persistence were not evaluated. There are limitations to the study design as a cross-sectional study with a descriptive design, and there is no adjustment for plausible confounders. Overall, there may be many additional factors influencing the treatment that were not captured in the survey. For example, it was not assessed 
how often the participants inject and/or at what time of the day; this could have an influence on the persistence patterns.

\section{CONCLUSION}

This study showed the real-world experiences of T2DM patients with different persistence behaviors after initiating basal insulin in Brasil. Fewer concerns were reported by continuers before and after insulin initiation than interrupters and discontinuers. The benefits of basal insulin therapy motivated continuers to persist with the treatment; experienced or anticipated side effects contributed to interruption and discontinuation. It was observed that physicians/HCPs interactions have an important role in initiating and ensuring adherence to insulin therapy. Further, patient training, including discussing their challenges and fears, and setting realistic expectations of insulin, may motivate patients to initiate and adhere to insulin therapy.

\section{Acknowledgments}

The authors would like to thank Irene Hadjiyianni, MD, Eli Lilly, Germany, for the contributions to the study design and advice with this publication. The authors also thank Sara Fonseca Jung, MD, Eli Lilly Brasil, for revisions of this publication.

Simone Wille, MA, from Eli Lilly and Company provided medical writing assistance. This study was funded by Eli Lilly and Company.

\section{Conflict of Interest}

Denis Reis Franco serves as an advisor for Abbott, Eli Lilly, and Sanofi, as a speaker for Abbott, Eli Lilly, Medtronic and Sanofi, and receives research grants from Eli Lilly, Novo Nordisk, and Sanofi. Magaly Perez-Nieves, Dachuang Cao, and Marcela Saturnino Caselato Vaz are full-time employees and hold shares of Eli Lilly. Jasmina I Ivanova is a former employee of Analysis Group, Inc, which received research funding for this study from Eli Lilly.

\section{RESUMO}

OBJETIVO: Dados de vida real sobre como a eficácia da terapia com insulina é afetada pela baixa persistência ao tratamento que ocorre logo após o início da terapia. Esta análise é a parte brasileira de um estudo transversal internacional conduzido em pacientes com DM2 que teve como objetivo descrever as razões relacionadas à não persistência ao tratamento com insulina.

METODOLOGIA: O estudo realizado em sete países por meio de questionários on-line classificou como pacientes continuadores (aqueles que não apresentaram intervalo $\geq 7$ dias sem uso da insulina), interrompedores (interromperam a terapia por $\geq 7$ dias nos primeiros seis meses de uso, depois recomeçaram) e descontinuadores (interromperam a terapia por $\geq 7$ dias nos primeiros seis meses de uso e não retornaram). Nesta análise descrevemos os dados da coorte brasileira.

RESULTADOS: Dos 942 pacientes incluídos, 156 eram do Brasil, com idade média de 34 anos e média de seis anos desde o diagnóstico de DM2. Razões que contribuíram para o uso contínuo da insulina $(n=50)$ foram a melhora do controle glicêmico (82\%) e a melhora no estado geral (50\%). Razões para a interrupção ( $n=51)$ ou para a descontinuação $(n=55)$ foram, respectivamente, ganho de peso $(41,7 \%$, $43,6 \%)$, hipoglicemia $(45,1 \%, 38,2 \%)$ e dor à aplicação (39,2\%, 49,1\%). Entretanto, nem todos os pacientes que reportaram ganho de peso e hipoglicemia como possível razão para interrupção ou descontinuação realmente apresentaram esses eventos: 16/24 (66,7\%) e 22/24 (91,4\%) dos participantes apresentaram ganho de peso e 13/23 (56,6\%) e 15/21 (71,4\%) apresentaram hipoglicemia, respectivamente. A razão mais importante para o possivel recomeço entre os interrompedores e descontinuadores foi a persuasão de médicos/profissionais de saúde (80,4\% e $72,7 \%$, respectivamente).

CONCLUSÕES: Os benefícios do tratamento com insulina basal motivaram continuadores a persistir com a terapia; a experiência ou a antecipação de eventos adversos contribuíram para a interrupção e descontinuação. O treinamento de médicos e pacientes é um dos pilares fundamentais do tratamento do diabetes.

PALAVRAS-CHAVE: Diabetes mellitus tipo 2. Insulina basal. Adesão à medicação.

\section{REFERENCES}

1. World Health Organization (WHO). Global report on diabetes. 2016 [cited 2019 Mar 05]. Available from: http://apps.who.int/iris/bitstream/ handle/10665/204871/9789241565257_eng.pdf?sequence=1.

2. International Diabetes Federation. IDF Diabetes Atlas. 2017; 8th ed. [cited 2019 Mar 05]. Available from: http://www.diabetesatlas.org

3. Almeida-Pititto B, Dias ML, Moraes AC, Ferreira SR, Franco DR, Eliaschewitz FG. Type 2 diabetes in Brazil: epidemiology and management. Diabetes Metab Syndr Obes. 2015;8:17-28.
4. Vencio S, Paldánius PM, Blüher M, Giannella-Neto D, Caiado-Vencio R, Strain WD. Understanding the barriers and improving care in type 2 diabetes: Brazilian perspective in time to do more in diabetes. Diabetol Metab Syndr. 2017;9:46.

5. Linetzky B, Curtis B, Frechtel G, Montenegro R Jr, Escalante Pulido M, Stempa $\mathrm{O}$, et al. Challenges associated with insulin therapy progression among patients with type 2 diabetes: Latin American MOSAlc study baseline data. Diabetol Metab Syndr. 2016;8:41. 
6. Coutinho WF, Silva júnior WS. Diabetes care in Brazil. Ann Glob Health. 2015;81(6):735-41.

7. Mourão $A O$, Ferreira WR, Martins MA, Reis $A M$, Carrillo MR, Guimarães AG, et al. Pharmaceutical care program for type 2 diabetes patients in Brazil: a randomised controlled trial. Int J Clin Pharm. 2013;35(1):79-86.

8. Lerario AC, Chacra AR, Pimazoni-Netto A, Malerbi D, Gross JL, Oliveira JE, et al. Algorithm for the treatment of type 2 diabetes: a position statement of Brazilian Diabetes Society. Diabetol Metab Syndr. 2010;2(1):35.

9. Mendes AB, Fittipaldi JA, Neves RC, Chacra AR, Moreira ED Jr. Prevalence and correlates of inadequate glycaemic control: results from a nationwide survey in 6,671 adults with diabetes in Brazil. Acta Diabetol. 2010;47(2):137-45

10. Guzmán JR, Lyra R, Aguilar-Salinas CA, Cavalcanti S, Escaño F, Tambasia M et al. Treatment of type 2 diabetes in Latin America: a consensus statement by the medical associations of 17 Latin American countries. Latin American Diabetes Association. Rev Panam Salud Publica. 2010;28(6):463-71.

11. Inzucchi SE, Bergenstal RM, Buse JB, Diamant M, Ferrannini E, Nauck M, et al. Management of hyperglycemia in type 2 diabetes, 2015: a patient-centered approach: update to a position statement of the American Diabetes Association and the European Association for the Study of Diabetes. Diabetes Care. 2015;38(1):140-9.

12. Peyrot M, Perez-Nieves M, Ivanova J, Cao D, Schmerold L, Kalirai S, et al. Correlates of basal insulin persistence among insulin-naïve people with type 2 diabetes: results from a multinational survey. Curr Med Res Opin. 2017;33(10):1843-51.

13. Eliaschewitz FG, Paula MA, Pedrosa HC, Pires AC, Salles JEN, Tambascia $M A$, et al. Barriers to insulin initiation in elderly patients with type 2 diabetes mellitus in Brazil. Diabetes Metab Syndr. 2018;12(1):39-44.

14. Peyrot M, Rubin RR, Lauritzen T, Skovlund SE, Snoek FJ, Matthews DR, et al; International DAWN Advisory Panel. Resistance to insulin therapy among patients and providers: results of the cross-national Diabetes Attitudes, Wishes, and Needs (DAWN) study. Diabetes Care. 2005;28(11):2673-9.

15. Perez-Nieves M, Kabul S, Desai U, Ivanova II, Kirson NY, Cummings AK, et al. Basal insulin persistence, associated factors, and outcomes after treatment initiation among people with type 2 diabetes mellitus in the US. Curr Med Res Opin. 2016;32(4):669-80

16. Hadjiyianni I, Desai U, Ivanova JI, Kirson NY, Enloe C), Cummings AG, et al. Basal insulin persistence, associated factors, and outcomes after treatment initiation among people with type 2 diabetes mellitus in Japan. Value Health. 2015;18(7):A611-2

17. Ascher-Svanum H, Lage MJ, Perez-Nieves M, Reaney MD, Lorraine J, Rodriguez $\mathrm{A}$, et al. Early discontinuation and restart of insulin in the treatment of type 2 diabetes mellitus. Diabetes Ther. 2014;5(1):225-42.

18. Perez-Nieves M, Ivanova II, Hadjiyianni I, Zhao C, Cao D, Schmerold L, et al. Basal insulin initiation use and experience among people with type 2 diabetes mellitus with different patterns of persistence: results from a multi-national survey. Curr Med Res Opin. 2017;33(10):1833-42.

19. Viana LV, Leitão CB, Kramer CK, Zucatti AT, Jezini DL, Felício I, et al. Poor glycaemic control in Brazilian patients with type 2 diabetes attending the public healthcare system: a cross-sectional study. BMJ Open. 2013;3(9):e003336

20. Rubin RR, Peyrot M. Factors affecting use of insulin pens by patients with type 2 diabetes. Diabetes Care. 2008;31(3):430-2.

21. Valle Nascimento TM, Resnicow K, Nery M, Brentani A, Kaselitz E, Agrawal P, et al. A pilot study of a Community Health Agent-led type 2 diabetes self-management program using Motivational Interviewing-based approaches in a public primary care center in São Paulo, Brazil. BMC Health Serv Res. 2017;17(1):32.

22. Ng C), Lai PS, Lee YK, Azmi SA, Teo CH. Barriers and facilitators to starting insulin in patients with type 2 diabetes: a systematic review. Int I Clin Pract. 2015;69(10):1050-70. 